\title{
Efficiency Advantages and Incentive Mechanism of PPPs: A Qualitative Comparative Analysis under the Chinese Scenario
}

\author{
Xiaowei Dong (D), Yali Du $(\mathbb{D}$, and Xianhua Wu \\ Investment Project Management Institute, Dongbei University of Finance \& Economics, Dalian 116025, China \\ Correspondence should be addressed to Yali Du; duyali58@163.com
}

Received 20 April 2018; Revised 29 May 2018; Accepted 13 June 2018; Published 1 August 2018

Academic Editor: Xianbo Zhao

Copyright (C) 2018 Xiaowei Dong et al. This is an open access article distributed under the Creative Commons Attribution License, which permits unrestricted use, distribution, and reproduction in any medium, provided the original work is properly cited.

\begin{abstract}
Based on the PPP efficiency system which consists of allocation efficiency, process efficiency, and individual efficiency, we use qualitative comparison analysis of fuzzy sets to study the efficiency advantages of the public-private partnership under the Chinese scenario. The findings are as follows: (1) like public-private partnerships, Chinese-style PPPs have also failed to achieve cooperation. (2) High allocation efficiency can be achieved if competition in bidding processes can be ensured; when bidding procedures cannot be guaranteed to compete, alternatives to high allocation efficiency are either privatized or allocated directly to enterprises that can enable economies of scale; individual effort is a source of allocation efficiency. (3) Competition and economies of scale are necessary conditions for high process efficiency. The private sector's ownership of assets is a sufficient condition for high process efficiency. (4) High individual efficiency can be achieved if individual efforts can be ensured, and high individual efficiency can also be achieved by the competition of bidding procedures or economies of scale when it is impossible to ensure high levels of individual effort. Privatization is the perfect incentive for high individual efficiency when the competition in the bidding process, individual efforts, and economies of scale cannot be guaranteed.
\end{abstract}

\section{Introduction}

The government and enterprises (includes state-owned enterprises and private enterprises) cooperation model, which is Chinese-style public-private partnerships, has been rapidly developed and widely used. Public-private partnerships (PPPs) have received increasing attention in China because they are thought to have many benefits $[1,2]$. Using PPPs, governments can obtain funds, advanced management, and technologies from enterprises, benefits from cost savings, and on time project delivery [3-5]. Involving the private sector in infrastructure projects will lead to higher quality service delivery, lower administrative costs, will also enable the transfer of risks to private sectors, and "value-for-money" [6-9]. Most of the above advantages of PPPs are efficiency issues, compared to traditional public-sector provision; efficiency and productivity improvement are the fundamentals of PPPs [10]. However, this is not a natural and unquestioned proposition [11-13]. At the same time, private enterprises may obtain no gain from improving efficiency; it is fixed at a specific level by the concession agreement in a PPP project.
The reason for involvement of the private sectors is that they are uniquely determined in the presence of the difference between the efficiency of traditional provision and PPPs approach. The differences are reflected in the theoretical efficiency advantages and the undoubtedly high transaction costs [14]. Given the obvious complexity, PPPs have higher transaction costs than traditional public procurement. According to Allen (2001), bidding costs to all potential contractors have reached as much as 3 percent of expected total project costs, regardless of project size, which is 3 times higher than in traditional provision [15]. Besides, a PPP project has higher monitoring costs, and empirical evidence from the United States shows that monitoring performance of the private sector partner in PPPs projects entails extra costs anywhere between 3 and 25 percent of the contract value [16]. PPPs have higher transaction costs, which needs no further discussion.

In contrast, applicability of PPPs depends on whether it can realize potential efficiency advantages or not. Especially in the context of China, state-owned enterprises have also been seen as the private sector; therefore, Chinese-style 
public-private partnerships has distinct internal configuration, and the efficiency advantages of Chinese-style PPPs will be different. Meanwhile, efficiency advantages and incentive issues are two sides of a coin for the application of PPPs. Efficiency is a question of economics, while motivation is about management. It means that we can improve the efficiency of PPPs projects by stimulating private sectors; it also means that we can explore and unearth more other sources of advantages by using incentive mechanisms. The research question for this study is, "Compared to traditional procurement, what kind of efficiency advantages does Chinese-style PPPs have? And what are the incentives that are consistent with these efficiency advantages?"

This article is structured as follows: Section 2 describes efficiency of PPPs projects, its implications for the research approach, and the applied research approach of fuzzy-set Qualitative Comparative Analysis (fsQCA). Section 3 sets the empirical scene by introducing the process of survey and the data collection. Section 4 analyzes data using the fsQCA method. Sections 5 and 6 comprise the discussion and conclusions, respectively.

\section{Efficiency of PPP Projects}

2.1. Efficiency System of PPPs Project. Partners from different sectors in PPPs may bring distinctive advantages to collaborative endeavor $[17,18]$. Public-sector partners hold particular mandates or powers [19], which enable them to target at special issues, such as situations of market failure; private sector partners may possess the ability to maximize value for money and thus deliver outcomes at lower cost [20, 21]. In PPPs, the public-sector safeguards allocative efficiency and the private sector ensure productive efficiency [10]. Free competition market without public-sector intervention provides the most efficient way to allocate scarce economic resources to competing uses. Therefore, under the hypothesis of efficient market, allocative efficiency and production efficiency cannot be divided into two branches that are separately responsible for different subjects. For infrastructure and public services, this distinction provides an excellent research perspective.

However, the distinction between allocation efficiency and production efficiency benefits economic explanations but does not contribute to project management. To compensate for this defect, following the above logic, we elaborate the rule that different subjects dominate different types of efficiency. First of all, the atomic decision-making units are the individuals rather than the public or private organizations [22]. The efficiency associated with it is clearly different from the allocation efficiency, because initially we were not sure what the source of this particular efficiency was, and Leibenstein called it X-efficiency [23]. However, this efficiency is ultimately reflected in the autonomy of the individual, in the PPP project scenario, called the individual efficiency. Specific issues of the project also depend on the individual efforts; therefore, individual efficiency can be seen as an important part of production efficiency. Secondly, PPPs can be defined as cooperation between public and private actors with a durable character in which actors develop mutual products and services, and meanwhile, risk,
TABLE 1: Efficiency types and their subjects.

\begin{tabular}{lcc}
\hline Efficiency & Subjects & Stage of project \\
\hline $\begin{array}{l}\text { Allocation } \\
\text { efficiency }\end{array}$ & Public sector & Bidding stage \\
$\begin{array}{l}\text { Process efficiency } \\
\text { Individual } \\
\text { efficiency }\end{array}$ & Public and private sectors & Project life cycle \\
\hline
\end{tabular}

costs, and benefits are shared [24]. Cooperation reflects the fundamental value of PPPs, and separation of allocation efficiency and production efficiency reflects the division of labor, but it does not reflect cooperation. Process efficiency concept came into being, which emphasizes the efficiency of the project implementation process. Only effective cooperation can achieve process efficiency, and process efficiency is also an important part of production efficiency. According to different efficiency subjects, this paper expands the efficiency of PPP projects into a system that includes allocation efficiency, process efficiency, and individual efficiency. Table 1 provides an overview of efficiency types and its subjects.

The three efficiencies in this efficiency system have different theoretical foundations. Among them, allocation efficiency is based on the theory of Pareto efficiency, individual efficiency is derived from X-efficiency theory, and process efficiency is based on the cooperative concept advocated by the PPP model. Identifying efficiency subjects helps clarify the responsibilities of many participants in the PPP project. In a perfect competitive market or a pure public goods market, it is completely unnecessary to distinguish efficiency subjects. As a value-staggering approach, the PPPs need to take into account the attributes of the public sector and the private sector. Taken together, the unique PPP projects originate from the hybrid attributes of private goods and public goods, which is the theoretical basis of the efficiency system proposed in this paper.

2.2. Sources of Efficiency Advantage and Incentives. When it comes to the term efficiency advantage, it implies a comparison to the traditional provision. In typical PPPs, private sector organizations operate in an economic environment of contestable resource markets. Pressure to maximize the value of shareholders together with the threat of mergers and acquisitions should ensure that the value is maximized from resources controlled by the private sector [25, 26]. With fewer formal decision-making procedures and less administrative oversight, the private sector can be less hampered by bureaucratic rules and controls [27]. Therefore, the earlier research was based on the comparison between government attributes and market attributes, and it was believed that PPPs have efficiency advantages. Besides, Hart took an incomplete contract as a research perspective, and believed that the choice between PPPs and conventional provision was made on whether it is easier to write contracts on service provision than on building provision; PPP is efficient if the quality of the service can be well specified in the initial contract [28].

Later studies have paid more and more attention to the project itself, which is the issue of economic characteristics of PPPs. Theorists attribute the private sector's efficiency 
advantages to three distinct mechanisms, which are contestability effect, ownership effect, and scale effect [29-34]. PPP is a procurement model in which the value for money is optimized through efficient allocation of risks, whole life service approach, private sector management skills as well as synergies from interlinking the design, finance, construction, and operations [35]. It can be summarized as a competitive tendering process [29], the binding of different project links [36,37], private ownership of project assets in a specific period, economies of scale, risk transfer [38-40], and cooperation $[24,41]$. In accordance with the viewpoint of Klijn and Teisman, due to the different core business between the public and private sectors, different values and strategies, joint decision-making is impossible, and cooperation is difficult to achieve [24]. At the same time, ownership and binding are not suitable for separation processing; only when ownership is clear, binding can be realized, and only when binding is realized, ownership is meaningful. In addition, according to X-efficiency theory, PPPs may change the inert area [23] of the individual compared to the traditional provision methods, which means the improvement of individual efforts. And the individual effort may also come into the potential source of efficiency advantage of PPPs, and empirical studies support this view [42].

2.3. Configuration Ideas and $Q C A$. The efficiency advantages of typical PPPs may not be established in Chinese-style PPPs, and the efficiency advantages that are not established in typical PPPs may be realized under Chinese-style PPPs. In order to clarify the source of efficiency advantages of Chinese-style PPP, we conduct empirical research that includes all potential advantages. The empirical research is operated under the above efficiency system that consists of allocative efficiency, process efficiency, and individual efficiency. Efficiency is more likely to result from a combination of multiple efficiency advantages than a single efficiency advantage. Therefore, this issue is related to complex cause and effect rather than simple one. Ragin believes that these issues are suitable for configuration analysis [43]. Qualitative comparative analysis (QCA) is a method of configuration analysis, which is a case-based comparative method. The core idea of QCA is the idea of configuration; it considers research objects as an inseparable organism. In mainstream applications, cases are the main research objects. However, the QCA method is not limited to case studies as long as it does not violate the concept that the object of analysis is an inseparable organism. This article treats each investigated individual as an indivisible research object, and this approach fully complies with the application logic of the QCA method. In other words, all the information provided by participants on PPPs is whole. The study strategy of discarding information fragmentation is abandoned.

Following the properties explained above, the research approach used for the present study consists of several steps [44]. The first step is about the grounded collection of data, which was conducted through a structured questionnaire. This allowed the researcher to obtain the participant's view, attitude, experience, and intuitive feeling about the PPP project which they take part. In the second step, the questionnaire information was qualitatively coded. Qualitative coding is a process where codes are developed and can be revisited as the researcher interprets the data [45]. The third step is the application of the QCA method, which is an umbrella term for several subtypes, including fsQCA [46]. Being case-based, it allows researchers to emphasize the unique aspects of cases, while still allowing the identification of patterns among them through comparison [45]. In QCA, the aspects of cases are named "conditions."

QCA analysis can also be divided into several subroutines. The first subroutine is the grounded cases as configurations, based on the coded structured questionnaire. The configurations are placed in a data matrix after coding cases quantitatively, and the cases are put in the rows and the conditions in the columns in the matrix. The second subroutine is to convert the data into so-called truth table, which sorts the cases over the logically possible configurations that are present in the data [47]. Each row in the truth table, which is a fundamental tool for the comparative analysis, can be read as a statement about whether the configuration represented in the row is "true" for the corresponding outcome. The third subroutine involves the pairwise comparison of configurations that have the same outcome but differ in one other condition, that is, the truth table minimization process. The last subroutine is to interpret the patterns that result from the truth table minimization so as to understand the efficiency advantage sources of corresponding type efficiency in this study.

\section{Data Collection}

3.1. Research Background Information. This article examines the sources of efficiency advantages of the PPP approach under the Chinese scenario. In other words, PPP is seen as a relatively abstract concept, rather than a specific project or a category of projects. Therefore, practitioners and researchers who have a personal experience of Chinese-style PPPs are the most objective, and their attitudes and opinions can best reflect China's reality. According to the logic of the QCA method, this article regards everyone's evaluation and views on related issues as an integral organism. In case study terminology, this article treats the view of each participant or researcher involved as a case.

The data needed for the study was obtained through a structured questionnaire. The study population was focused on PPP researchers in universities and research institutes and PPP practitioners in the government sector, private sector, consulting agencies, and financial institutions. The survey lasted for more than six months; 236 questionnaires were distributed and 211 were recovered, of which 174 were valid questionnaires. Because the QCA method is applicable to small-scale, medium-scale, and large-scale samples, the sample size can still be adjusted during the analysis process. At the same time, 174 valid samples are strictly screened through the time of answering questions, the number of years of employment, and reverse items. With the help of second-hand data such as specific project information and literature data, the 
TABLE 2: Sample background information.

\begin{tabular}{|c|c|c|c|}
\hline Types & Classification & Sample scale & Percentage \\
\hline \multirow{5}{*}{ Subject attributes } & Public sector & 16 & 19.5 \\
\hline & Private sector & 20 & 24.4 \\
\hline & Consulting agencies & 12 & 14.6 \\
\hline & Research institutes & 26 & 31.7 \\
\hline & Financial institutions & 8 & 9.8 \\
\hline \multirow{5}{*}{ Years of service } & Less than 1 year & 3 & 3.7 \\
\hline & 1 to 3 years & 29 & 35.4 \\
\hline & 4 to 6 years & 9 & 11.0 \\
\hline & 7 to 9 years & 7 & 8.5 \\
\hline & 10 years and above & 34 & 41.5 \\
\hline \multirow{5}{*}{ Subject's type of project } & Transportation project & 33 & 40.2 \\
\hline & Municipal related & 36 & 43.9 \\
\hline & Agriculture and environment related & 11 & 13.4 \\
\hline & Comprehensive development related & 19 & 23.2 \\
\hline & Social utilities and others & 33 & 40.2 \\
\hline
\end{tabular}

questionnaire was further reviewed and 82 samples were finally retained as analysis data. The corresponding background information of the structured questionnaire is shown in Table 2.

The background data from the subjects were found as follows: (1) the number of participants from governments, private sectors, and consulting agencies was 16, 20, and 12, which corresponded to $19.5 \%, 24.4 \%$, and $14.6 \%$, respectively. These three types of subjects were the most direct practitioners of the PPP program, and these proportions are relatively balanced. The highest proportion of subjects is the PPP researcher of scientific research institutions, which is $31.7 \%$. Its proportion is not dominant, and researchers receive comprehensive information from public sectors, private sectors, consulting agencies, financial institutions, and academics frontier. Researchers' attitudes are more neutral and objective than practitioners in other sectors and do not have a negative impact on research validity. (2) Judging from the types of participants involved in the project, the proportion of the five categories is relatively balanced, with the lowest share of the agriculture, forestry, and water conservancy projects being $13.4 \%$, which is related to the relatively small percentage of such projects. The above data are basically consistent with the project data released by the Ministry of Finance and the National Development and Reform Commission. (3) From the perspective of the practitioner's employment time, $61.0 \%$ of the employees had worked for more than 4 years. Another $35.4 \%$ of the participants had a working time of 1 to 3 years. This period is in line with the time the government has pushed PPPs. Therefore, $61.0 \%$ of the subjects have relatively rich project experience, and more than $96 \%$ of the subjects have a deeper understanding of PPPs, which means that the reliability of the survey data can be ensured.

3.2. Variables of Conditions and Outcomes. According to the previous argument, there are six variables in the preexisting conditions: competition, ownership and binding, risk transfer, economies of scale, cooperation, and individual efforts. Allocation efficiency, process efficiency, and individual efficiency are the outcome variables. In the structural questionnaire, each variable corresponds to some measurement items. Theoretically, there are two methods to determine the weight of each item. One option is to use the confirmatory factor analysis (CFA) to determine the factor load of each item and then use the factor load as the basis for calculating the weights, and another option is to determine weights by means of expert scoring. The former is based on statistical logic of random sampling, and the latter is based on subjective experience evaluation. Considering that the QCA method itself has a logical basis completely different from the mainstream statistical methods, and in order to better reflect the qualitative comparative characteristics of the QCA, the expert rating method is used in this paper to determine the weights. The corresponding condition variables and result variables are described in Table 3.

3.3. Data Calibration. Calibration is the process of data adjustment, so that by the calibration, results will have interpretability. The use of fuzzy-set calibration is based on some certain criteria to adjust the scores of the conditions and outcomes to the explainable affiliation, and the degree of membership is between 0 and 1, where 0 means completely nonaffiliated and 1 means completely subordinated. In the calibration procedure of the operating software fsQCA 2.0, it is necessary to set three thresholds that are completely unaffiliated, fully affiliated, and crossover points [43]. The three points in this article are set to 5,4 , and 1 , respectively, that is, a weighted average score of 5 means "completely subordinated", 1 means "completely unaffiliated", and an intersection 4 means "not totally subordinate or not completely nonaffiliated." The purpose of setting a higher intersection is to obtain more robust analysis results, as shown in Table 4:

\section{Analysis}

4.1. Necessity of Single Preconditions. For qualitative comparative analysis, causality is constructed through sufficient conditions and necessary conditions. If a condition always occurs when a result is produced, this condition is a necessary condition for the corresponding result; if a result is always produced when a condition occurs, then the condition is 
TABLE 3: Brief description of variables.

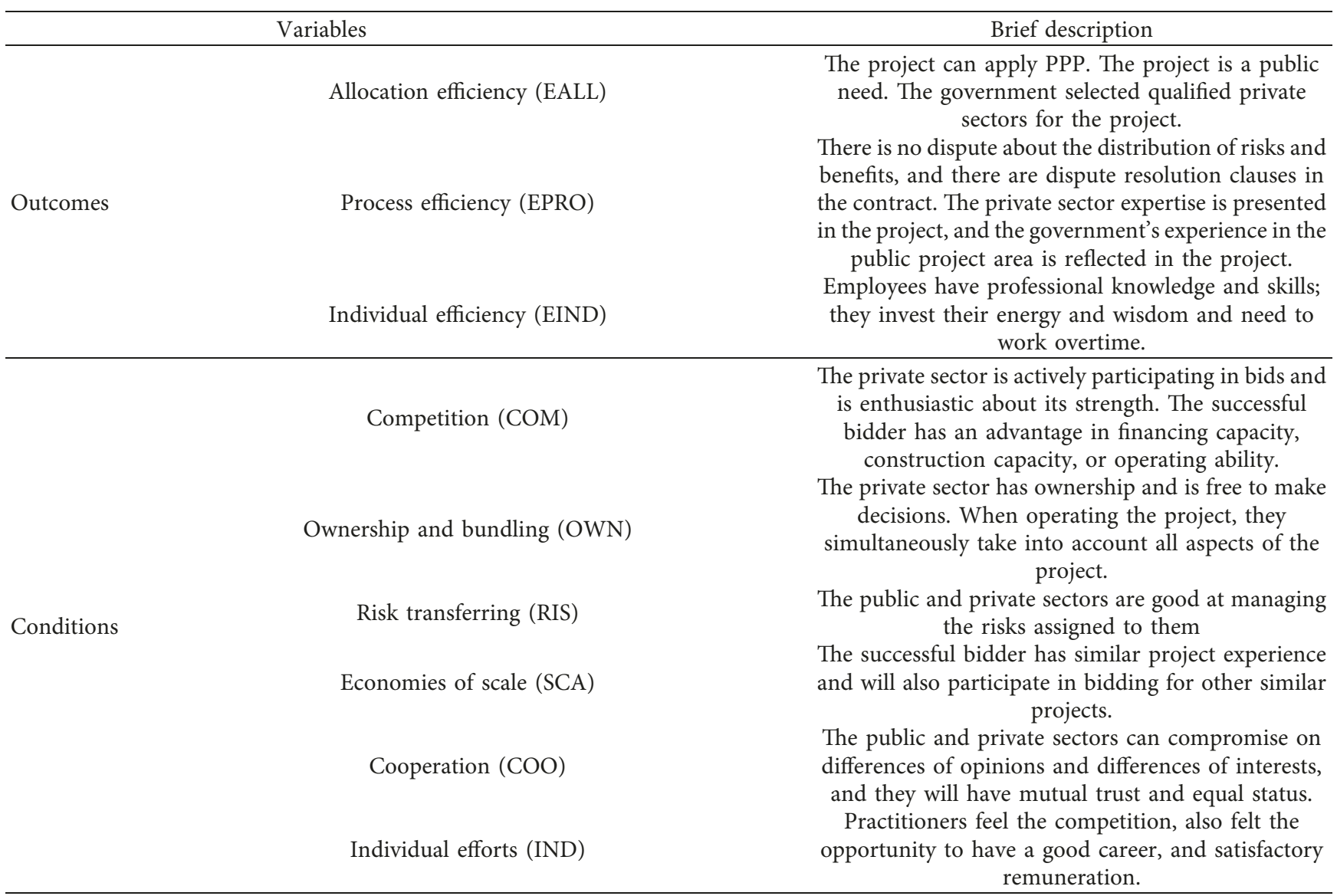

TABLE 4: Calibration guidelines.

\begin{tabular}{lccc}
\hline Variables & & Target set & Anchor points \\
\hline \multirow{4}{*}{ Outcomes } & Allocation efficiency (EALL) & High allocative efficiency & \\
& Process efficiency (EPRO) & High process efficiency & \\
& Individual efficiency (EIND) & High individual efficiency & \\
& Competition (COM) & Perfect competition & 5 means completely subordinated; 1 means \\
& Ownership and bundling & Property rights are clear and ideally & completely unaffiliated; and an intersection 4 \\
Conditions & means the crossover points \\
& Risk transferring (RIS) & Reasonable risk transfer & \\
& Economies of scale (SCA) & With economies of scale & \\
& Cooperation (COO) & Effective cooperation & \\
& Individual efforts (IND) & High-level individual effort & \\
\hline
\end{tabular}

a sufficient condition for the corresponding result. The necessary condition is an indispensable condition that leads to the occurrence of the result, but it does not mean that the result will inevitably occur. Based on the assumptions of multiple concurrent causalities, the necessary and sufficient conditions in social sciences do not exist. The QCA analysis seeks causality by establishing a combination of sufficient conditions. Therefore, it is necessary to determine whether the conditions of each antecedent condition variable are the necessary conditions for the outcome variable. If it is a necessary condition, it may not be considered when searching for a sufficient conditional combination later. The condition variable is a necessary condition for the corresponding result, when the current consistency between the condition variable and the result variable reaches 0.9 [48]. Necessity of calculation software derived from single condition is shown in Table 5. According to the standard of consistency 0.9, competition is a necessary condition for process efficiency. Weak cooperation or noncooperation is a necessary condition for high allocation efficiency, high process efficiency, and high individual efficiency. This means that in the current stage of Chinese-style PPPs, the degree of collaborative cooperation is still low. Cooperation has not become a source of Chinesestyle PPP's efficiency advantage. It is difficult to achieve effective cooperation under the Chinese scenario, like the Western developed countries. 
TABLE 5: The necessity of single preconditions.

\begin{tabular}{|c|c|c|c|c|}
\hline \multirow{3}{*}{ Conditions } & & \multicolumn{3}{|c|}{ Outcomes } \\
\hline & & \multicolumn{3}{|c|}{ Necessity } \\
\hline & & Allocation efficiency & Process efficiency & Individual efficiency \\
\hline \multirow{2}{*}{ Competition } & $\mathrm{COM}$ & 0.85 & 0.93 & 0.79 \\
\hline & $\sim \mathrm{COM}$ & 0.81 & 0.82 & 0.78 \\
\hline \multirow{2}{*}{ Ownership and bundling } & OWN & 0.62 & 0.76 & 0.59 \\
\hline & $\sim \mathrm{OWN}$ & 0.93 & 0.92 & 0.89 \\
\hline \multirow{2}{*}{ Risk transferring } & RIS & 0.81 & 0.88 & 0.79 \\
\hline & $\sim \mathrm{RIS}$ & 0.83 & 0.84 & 0.78 \\
\hline \multirow{2}{*}{ Economies of scale } & SCA & 0.87 & 0.90 & 0.84 \\
\hline & $\sim$ SCA & 0.77 & 0.80 & 0.73 \\
\hline \multirow{2}{*}{ Cooperation } & $\mathrm{COO}$ & 0.51 & 0.62 & 0.47 \\
\hline & $\sim \mathrm{COO}$ & 0.95 & 0.98 & 0.95 \\
\hline \multirow{2}{*}{ Individual efforts } & IND & 0.80 & 0.86 & 0.77 \\
\hline & $\sim \mathrm{IND}$ & 0.81 & 0.85 & 0.79 \\
\hline
\end{tabular}

Note: preceding a variable, the symbol " " represents the logical operator "NOT."

TABLE 6: The configuration of allocation efficiency.

\begin{tabular}{|c|c|c|c|c|c|c|c|}
\hline \multirow{2}{*}{ Conditions } & \multicolumn{7}{|c|}{ Configuration } \\
\hline & EALL1 & EALL2 & EALL3 & EALL4 & EALL5 & EALL6 & EALL7 \\
\hline $\mathrm{COM}$ & $\otimes$ & & 8 & $\otimes$ & $\otimes$ & & \\
\hline OWN & $\otimes$ & $\otimes$ & $\otimes$ & 0 & & & \\
\hline RIS & & $\otimes$ & $\otimes$ & $\otimes$ & & & \\
\hline SCA & $\otimes$ & 0 & & $\otimes$ & & & \\
\hline IND & & $\otimes$ & $\otimes$ & $\otimes$ & $\otimes$ & $\otimes$ & \\
\hline Consistency & 0.89 & 0.85 & 0.87 & 0.92 & 0.95 & 0.94 & 0.91 \\
\hline Coverage & 0.62 & 0.69 & 0.67 & 0.45 & 0.50 & 0.46 & 0.64 \\
\hline Overall solution consistency & & & & 0.80 & & & \\
\hline Overall solution coverage & & & & 0.87 & & & \\
\hline
\end{tabular}

Note: $\bigcirc$ indicates that the corresponding conditions exist. $\otimes \otimes$ means the corresponding conditions do not exist. $\otimes$ refers to the core condition. refers to the auxiliary conditions. No marking means that the corresponding condition does not matter.

4.2. High Efficiency Configuration. In the efficiency configuration analysis, the consistency threshold was set to 0.80 and the sample threshold was set to 1. According to this standard, the sample sizes in the allocation efficiency configuration, process efficiency configuration, and individual efficiency configuration were 25, 40, and 25, respectively. Analysis software usually gives complex solutions, simple solutions, and intermediate solutions for qualitative comparative analysis. The intermediate solution is the main basis for the QCA method, because it can avoid the cumbersome nature of the complex solution and the irrational nature of simple solution. From the analysis above of the necessary conditions, it can be inferred that weak cooperation is a necessary condition for all three types of efficiency. In addition, competition and economies of scale are also necessary conditions for process efficiency. Therefore, in the analysis of sufficient conditions, which is the analysis of the efficiency configuration, the effects of cooperation variables are ignored. When analyzing the process efficiency configuration, the impact of competition variables and economies of scale should be ignored, which is for the reason that they must exist in the corresponding efficiency configuration and do not require redundant analysis. High allocative efficiency configuration arranged is shown in Table 6.
Consistency and coverage are an important basis to evaluate the relationship between conditional configuration and outcomes. It can be seen from Table 6 that the consistency of all 7 conditional configurations is greater than the theoretical value of 0.8 , which means that the samples of these 7 conditional configurations all meet the consistency requirements. These 7 configurations are all sufficient conditions for the high allocation efficiency of PPP projects. The overall consistency index is also greater than 0.8 , further indicating that the resulting conditional configuration is a sufficient condition for high allocation efficiency. Coverage measures the extent to which the conditional configuration interprets the result. The greater the coverage is, the greater the interpretation of the result by the corresponding configuration will be.

The process efficiency configuration is shown in Table 7. There is only a sufficient condition for process efficiency configuration. It consists of three variables, of which ownership and bundling are core conditions, individual effort is an auxiliary condition, and risk transfer is not important to the configuration. Configuration consistency of 0.86 , more than the theoretical value 0.8 , the resulting configuration is indeed the sufficient condition for high 
TABLE 7: The configuration of process efficiency.

\begin{tabular}{lc}
\hline Conditions & $\begin{array}{c}\text { Configuration } \\
\text { EPRO1 }\end{array}$ \\
\hline OWN & \\
RIS & \\
IND & $\otimes$ \\
Consistency & 0.86 \\
Coverage & 0.71 \\
Overall solution consistency & 0.86 \\
Overall solution coverage & 0.71 \\
\hline
\end{tabular}

Note: $\bigcirc$ indicates that the corresponding conditions exist. $\otimes \otimes$ means the corresponding conditions do not exist. $\otimes$ refers to the core condition. $\otimes$ refers to the auxiliary conditions. No marking means that the corresponding condition does not matter.

efficiency of the process, and the configuration of coverage of 0.71. Considering that process efficiency emphasizes the project implementation process and cooperation process, which is, the effectiveness of integrating different links of projects, it depends more on management technology than on individual efforts. The private sector tends to use advanced management techniques when they have the project asset ownership.

Without the involvement of the variable of cooperation, the analysis of individual efficiencies finally yielded seven high-efficiency conditional configurations consisting of the other five conditions, as shown in Table 8. In these configurations, competition, ownership and bundling, economies of scale and individual efforts are the core conditions, and risk transfer is an auxiliary condition. The consistency of the configurations is greater than the theoretical value of 0.8 , which is a sufficient condition for high individual efficiency. The overall solution consistency was 0.86 , which also exceeded the theoretical value of 0.8 . The overall solution coverage was 0.84 , which represents the degree of interpretation of configurations.

Individual efficiency and allocation efficiency have a high degree of similarity only from the perspective of the configuration, the reason for which is that high allocation efficiency results from a competitive tendering process; the private sector will translate this competitive pressure into higher individual efforts, ultimately reflected in the higher individual efficiency. Therefore, the internal mechanism is completely different regardless of the similar configuration. In the discussion section of the paper, there will be more detailed derivation on the above three efficiency configurations.

\section{Discussion}

5.1. Discussion of the Results. The configuration above is an evaluation of the current Chinese-style PPP by practitioners and researchers, reflecting their attitudes and opinions. In the PPP project efficiency system which consists of allocation efficiency, process efficiency and individual efficiency, weak cooperation is a necessary condition for project efficiency. This article does not support the opinion that cooperation is a source of Chinese-style PPP's efficiency advantages. In public-private partnerships, the reason why cooperation is difficult to be achieved lies in the huge differences in the core business, values, and strategies between the public and private sectors. But under the Chinese scenario, we speculate that it has completely different causes. In China's PPP practice, state-owned enterprises dominate the private sector. There are no irreconcilable differences between the public and private sectors in values, strategies, and interests. The public sector and state-owned enterprises are more closely related to administrative affiliation than to equal cooperation. Based on the reality mentioned above, the public sector is accustomed to its strong position and the private sector is accustomed to its subordinate status, and cooperation will be difficult to achieve as well. According to discussion above, a proposition on cooperation can be drawn. In the following part, cooperation is no longer discussed.

Proposition 1. Like public-private partnerships, Chinesestyle PPPs are also difficult to achieve true joint decisionmaking and joint actions. Cooperation is not a source of efficiency advantages for Chinese-style PPPs.

5.1.1. Configuration of Allocation Efficiency. PPPs are mainly used in infrastructure and public service areas which have strong public good characteristics. These are areas where the private sector leads to supply shortages and efficiency losses. In order to avoid the loss of allocation efficiency, the allocation process is implemented by the government through a competitive bidding process. Obviously, competition is the core condition for configuration efficiency, and all the configurations of high allocation efficiency are further classified and merged according to whether competition conditions exist or not. When competition conditions exist, that is, under the condition that the competitiveness of the tendering stage can be guaranteed, the configuration 3, configuration 6 , and configuration 7 are obtained. The combination of these three configurations found that, as long as the competition in the tendering stage is ensured, a higher allocation efficiency can be achieved regardless of the existence of other conditions such as individual effort, scale economy, and risk transfer. If competition conditions do not exist, that is, when it is not possible to ensure the competitiveness of the bidding stage, the results are configuration 1, configuration 4, and configuration 5. Configuration 1 emphasizes individual effort, which means that even if other conditions are not met, high configuration efficiency can still be achieved as long as a high level of individual effort is ensured. However, what can only be determined is that individual efforts are the source of allocation efficiency; we cannot recognize the intrinsic link between individual efforts and other conditions. The combination of configuration 4 and configuration 5 emphasizes ownership and binding, which is highly compatible with the privatization or BOO (Build-Operate-Own) model in practice. In other words, even if it is not possible to ensure competitiveness, only if the privatization of related assets can be achieved, a high level of allocation efficiency can be achieved, and the resource allocation process is closer to the market mechanism. If the competition in the tendering stage is irrelevant, without other conditions, it corresponds to the 
TABLE 8: The configuration of individual efficiency.

\begin{tabular}{|c|c|c|c|c|c|c|c|}
\hline \multirow{2}{*}{ Conditions } & \multicolumn{7}{|c|}{ Configuration } \\
\hline & EIND1 & EIND2 & EIND3 & EIND4 & EIND5 & EIND6 & EIND7 \\
\hline $\mathrm{COM}$ & $\otimes$ & & 0 & $\otimes$ & $\otimes$ & 0 & \\
\hline OWN & $\otimes$ & $\otimes$ & $\otimes$ & 0 & & & $\otimes$ \\
\hline RIS & & $\otimes$ & $\otimes$ & $\otimes$ & 0 & 0 & 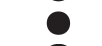 \\
\hline SCA & $\otimes$ & 0 & & $\otimes$ & O & $\otimes$ & \\
\hline IND & O & $\otimes$ & $\otimes$ & $\otimes$ & $\otimes$ & $\otimes$ & \\
\hline Consistency & 0.93 & 0.89 & 0.89 & 0.96 & 0.98 & 0.98 & 0.97 \\
\hline Coverage & 0.59 & 0.62 & 0.62 & 0.43 & 0.47 & 0.44 & 0.62 \\
\hline Overall solution consistency & & & & 0.86 & & & \\
\hline Overall solution coverage & & & & 0.84 & & & \\
\hline
\end{tabular}

Note: $\bigcirc$ indicates that the corresponding conditions exist. $\otimes \otimes$ means the corresponding conditions do not exist. $\otimes$ refers to the core condition. $\otimes$ refers to the auxiliary conditions. No marking means that the corresponding condition does not matter.

situation of configuration 2. Direct allocation of resources to the private sector with economies of scale, from the perspective of allocative efficiency, is equally efficient. Therefore, the following proposition about allocation efficiency is drawn.

Proposition 2. Competitiveness leads to high allocation efficiency, regardless of the existence of other conditions.

Proposition 3. Individual effort is the source of allocative efficiency.

Proposition 4. If competition cannot be ensured, but privatization is suitable, then privatization leads to effective allocation.

Proposition 5. When competition is irrelevant and not suitable for privatization, risk transfer and individual efforts cannot be guaranteed, and project allocation to the private sector with economies of scale is also effective.

5.1.2. Configuration of Process Efficiency. Competition and economies of scale are also necessary conditions for high process efficiency, which means high process efficiency can be achieved only if competitive and economies of scale are ensured. Under the above premise, only a sufficient conditional configuration of high process efficiency is obtained, that is, the configuration conditions of ownership and nonindividual efforts result in high process efficiency of PPP projects. The effectiveness of PPP needs to give the private sector sufficient free decision-making space and clear attribution of ownership. Although the emergence of nonindividual conditions has puzzled us, process efficiency focuses on the convergence of different aspects of the project and emphasizes the implementation process of the partnership. As a result, individual efforts that are out of step or even contrary to the project plan may harm process efficiency. The proposition about process efficiency is as follows:

Proposition 6. Competition, economies of scale, ownership and bundling are sources of process efficiency.
Proposition 7. High process efficiency can be achieved only if competitive and economies of scale are ensured.

5.1.3. Configuration of Individual Efficiency. The theoretical basis of individual efficiency is Leibenstein's X-efficiency theory. Depending on whether it is based on theory or the results of fuzzy-set qualitative comparative analysis, individual efforts are the core conditions of individual efficiency. Therefore, the resulting configuration is classified and merged based on whether individual efforts exist. If the core condition exists, corresponding to configuration 1 and configuration 7 , the combination of the two means that the configuration condition of high individual efficiency is individual effort and nonownership. Considering China's practice, the public sector has ownership in many cases, and the private sector cannot decide freely on their own. Nonownership conditions are therefore highly modeled on China's practice, and individual efforts are the key source of individual efficiency.

When the individual effort does not exist, it corresponds to the case of configurations 2, 3, 4, 5, and 6. They are further categorized and merged based on whether ownership conditions are met. Among them, the ones that are more in line with China's practice are the nonownership ones corresponding configuration 2 and configuration 3. Mergers can be achieved, as long as they have economies of scale and competitive characteristics, even if it is difficult to ensure individual efforts, ownership, and risk transfer, and high individual efficiency can still be achieved. It can be inferred that economies of scale and competition have produced effective incentives for individuals. In addition, configuration 4 can be interpreted alone as being suitable for privatization. The private sector is more adept at motivating individuals and making more efforts than the public sector, so other conditions are not important. Configuration 5 and configuration 6 mean that for those projects which do not ensure individual efforts, the private sector has more autonomy, and clears risk transfer, if the bidding process is competitive or the economy of scale is reached, it can also achieve high individual efficiency, which still embodies the incentive effect of competition and economies of scale on individuals. Based on the above derivation, the propositions on individual efficiency are as follows: 
Proposition 8. Individual efforts lead to individual efficiency even if other conditions do not exist.

Proposition 9. If individual efforts cannot be ensured, additional incentives are needed to achieve individual efficiency and competition and economies of scale are effective incentives.

Proposition 10. Privatization is the perfect incentive for high individual efficiency if the project is suitable for privatization.

All the discussion and propositions above rarely involve risk transfer. The reason is that in our efficiency system, risk transfer is only an auxiliary condition for the efficiency configuration. After the configuration classification is merged, the condition will be degraded. In practice, the basic principles and implementation rules for risk allocation and risk transfer are relatively clear and can be widely accepted, and risk transfer problems can be better resolved.

5.2. Efficiency Advantage and Incentive. From the perspective of overall project efficiency, competition, individual effort, ownership and bundling, economies of scale, and risk transfer are sources of PPP's efficiency advantage. It is because these mechanisms motivate participants by way of efficient implementation of the project. Each efficiency advantage can be seen as an incentive mechanism, in a sense, PPPs are an organic combination of multiple incentive mechanisms. Especially for individual efficiency configurations, the derivation to the final settlement is always an incentive for individuals. At the same time, we also noticed that all efficiency advantages are related to the private sector, and the corresponding incentives are also incentives for the private sector.

The enlightenment from the above discussion is that if we cluster the clear efficiency advantage into a more abstract incentive mechanism, we can in turn explore more potential efficiency advantages based on the incentive mechanism. The three incentive mechanisms of competitive incentives, intrinsic motivations, and extrinsic motivations can describe all the above efficiency advantages. According to Ryan and Deci, since the material or nonmaterial incentives are all externally controlled, they indirectly satisfy people's psychological or physiological needs, which are called extrinsic motivations [49]. Interests related to the project implementation process itself and feelings of satisfaction and achievement after solving difficult problems will also urge practitioners to move forward, saying it was an intrinsic motivation. The competition itself belongs to extrinsic motivations, considering that the competition of PPP mainly manifests itself as a competitive bidding process, and in view of the importance of competition to the three types of efficiencies in this paper, the competitive incentive is promoted to the same position as the other two.

Among the efficiency advantages identified in this paper, competition is simultaneously affiliated with competition incentives and extrinsic motivations, individual efforts are affiliated with competition incentives, extrinsic motivations, and intrinsic motivations, and ownership and binding are affiliated with extrinsic motivations and intrinsic motivation, economies of scale and risk transfer are extrinsic motivations. Mainstream economics always emphasize extrinsic motivations more. However, it is difficult to achieve effective cooperation under external incentives. For infrastructure projects and public service projects, high efficiency also requires internal incentives. For greater efficiency, we need to explore and apply efficiency advantages derived from internal incentives.

\section{Conclusion}

This article examines the sources of efficiency advantages of Chinese-style PPP. The efficiency of PPPs is expanded to a system that includes allocation efficiency, process efficiency, and individual efficiency. Based on the configuration idea and fuzzy-set of qualitative comparative analysis method, each efficiency configuration is studied. The study found that (1) competition, individual effort, ownership and bundling, and economies of scale are sources of high allocation efficiency, (2) competition, ownership and bundling, and economies of scale are sources of process efficiency, (3) individual efforts, competition, economies of scale, and ownership and bundling are sources of individual efficiency, (4) risk transfer is not an important source of efficiency advantage for Chinese-style PPP, and (5) like typical PPPs, Chinese-style PPP is also difficult to achieve effective cooperation. The three incentive mechanisms of competitive incentives, intrinsic motivations, and extrinsic motivations can describe all the above efficiency advantages. Its practical value lies in that we can not only use the already-existing efficiency advantages but also excavate more potential efficiency advantages based on incentive regulations.

As a compromise supply way of infrastructure and public service, the attractiveness of PPPs lies in the fact that it can theoretically absorb the advantages of traditional approach and purely private approach while avoiding their own shortcomings. But can it be ensured that the exact opposite would not occur? This article answers the question from the perspective of efficiency advantages and incentive mechanisms. Under the premise of following incentive regulations, as long as the existing and potential efficiency advantages can be fully exploited, PPPs have great potential.

\section{Data Availability}

The data used to support the findings of this study are included within the supplementary information file.

\section{Conflicts of Interest}

The authors declare that there are no conflicts of interest regarding the publication of this paper.

\section{Acknowledgments}

This research was funded by the Liaoning Province Social Science Planning Fund Project (Grant no. L16BJY022), 
Liaoning Provincial Department of Education General Research Project (Grant no. LN2016YB001), and Liaoning Provincial Financial Research Fund Project (Grant no. 17C028).

\section{References}

[1] T. Bovaird, "Public-private partnerships: from contested concepts to prevalent practice," International Review of Administrative Sciences, vol. 70, no. 2, pp. 199-215, 2004.

[2] Y. H. Kwak, Y. Y. Chih, and C. W. Ibbs, "Towards a comprehensive understanding of public private partnerships for infrastructure development," California Management Review, vol. 51, no. 2, pp. 51-78, 2009.

[3] A. R. Abdul-Aziz and P. S. J. Kassim, "Objectives, success and failure factors of housing public-private partnerships in Malaysia," Habitat International, vol. 35, no. 1, pp. 150-157, 2011.

[4] J. D. Donahue and R. J. Zeckhauser, Collaborative Governance: Private Roles for Public Goals in Turbulent Times, Princeton University Press, Princeton, NJ, USA, 2011.

[5] P. Bloomfield, "The challenging business of long-term public-private partnerships: reflections on local experience," Public Administration Review, vol. 66, no. 3, pp. 400411, 2006.

[6] R. G. Little, "The emerging role of public private partnerships in mega-project delivery," Public Works Management \& Policy, vol. 16, no. 3, pp. 240-249, 2011.

[7] G. A. Hodge and C. Greve, "Public-private partnerships: an international performance review," Public Administration Review, vol. 67, no. 3, pp. 545-558, 2007.

[8] D. Grimsey and M. K. Lewis, Public-Private Partnerships: The Worldwide Revolution in Infrastructure Provision and Project Finance, Edward Elgar Publishing, Cheltenham, UK, 2004.

[9] H. Christoffersen, M. Paldam, and A. H. Würtz, "Public versus private production and economies of scale," Public Choice, vol. 130, no. 3-4, pp. 311-328, 2007.

[10] T. Välilä, "How expensive are cost savings? On the economics of public-private partnerships," Eib Papers, vol. 10, no. 1, pp. 94-119, 2005.

[11] M. Torchia, "Public-private partnerships in the health care sector: a systematic review of the literature," Public Management Review, vol. 17, no. 2, pp. 236-261, 2015.

[12] C. Menard and S. Saussier, "Contractual choice and performance: the case of water supply in France: the case of water supply in France," Revue D Économie Industrielle, vol. 92, no. 1, pp. 385-404, 2000.

[13] M. Hellowell and A. M. Pollock, "The private financing of nhs hospitals: politics, policy and practice," Economic Affairs, vol. 29, no. 1, pp. 13-19, 2009.

[14] A. S. Soliño and P. G. D. Santos, "Transaction costs in transport public-private partnerships: comparing procurement procedures," Transport Reviews, vol. 30, no. 3, pp. 389-406, 2010.

[15] G. Allen, The Private Finance Initiative (PFI), House of Commons Research Paper 01/117, 2001.

[16] L. Torres and V. Pina, "Public private partnership and private finance initiatives in the EU and Spanish local governments," European Accounting Review, vol. 10, no. 3, pp. 601-619, 2001.

[17] J. W. Selsky and B. Parker, "Cross-sector partnerships to address social issues: challenges to theory and practice," Journal of Management, vol. 31, no. 6, pp. 849-873, 2016.
[18] J. Herranz, "The multisectoral trilemma of network management," Journal of Public Administration Research and Theory, vol. 18, no. 1, pp. 1-31, 2007.

[19] R. Andrews and T. Entwistle, "Does cross-sectoral partnership deliver? an empirical exploration of public service effectiveness, efficiency, and equity," Journal of Public Administration Research \& Theory, vol. 20, no. 3, pp. 679-701, 2010.

[20] N. Bilodeau, C. Laurin, and A. Vining, "“Choice of organizational form makes a real difference": the impact of corporatization on government agencies in Canada," Journal of Public Administration Research and Theory, vol. 17, no. 1, pp. 119-147, 2007.

[21] S. Cohen, "A strategic framework for devolving responsibility and functions from government to the private sector," Public Administration Review, vol. 61, no. 4, pp. 432-440, 2001.

[22] H. Leibenstein, "Competition and X-efficiency: reply," Journal of Political Economy, vol. 81, no. 3, pp. 765-777, 1973.

[23] H. Leibenstein, "Allocative efficiency V. X-efficiency," American Economic Review, vol. 56, 1966.

[24] E.-H. Klijn and G. R. Teisman, "Institutional and strategic barriers to public-private partnership: an analysis of dutch cases," Public Money and Management, vol. 23, no. 3, pp. 137-146, 2010.

[25] A. R. Vining and A. E. Boardman, "Ownership versus competition: Efficiency in public enterprise," Public Choice, vol. 73, no. 2, pp. 205-239, 1992.

[26] G. Hodge, "Contracting public sector services: a meta-analytic perspective of the international evidence," Australian Journal of Public Administration, vol. 57, no. 4, pp. 98-110, 2010.

[27] H. G. Rainey, "Public management: recent research on the political context and managerial roles, structures, and behaviors," Journal of Management, vol. 15, no. 2, pp. 229-250, 1989.

[28] O. Hart, "Incomplete contracts and public ownership: remarks, and an application to public-private partnerships*," Economic Journal, vol. 113, no. 486, pp. C69-C76, 2003.

[29] S. Domberger and P. Jensen, "Contracting out by the public sector: theory, evidence, prospects," Oxford Review of Economic Policy, vol. 13, no. 4, pp. 67-78, 1997.

[30] G. Bel, X. Fageda, and M. E. Warner, "Is private production of public services cheaper than public production? A metaregression analysis of solid waste and water services," Journal of Policy Analysis \& Management, vol. 29, no. 3, pp. 553-577, 2010.

[31] T. M. M. Kelnert and C. D. C. Silva, "Reinventing government: how the entrepreneurial spirit is transforming the public sector," Revista De Administração De Empresas, vol. 33, no. 6, pp. 97-99, 1993.

[32] A. Boitani, M. Nicolini, and C. Scarpa, "Do competition and ownership matter? Evidence from local public transport in Europe," Applied Economics, vol. 45, no. 11, pp. 1419-1434, 2013.

[33] R. Andrews and T. Entwistle, "Public-private partnerships, management capacity and public service efficiency," Policy \& Politics, vol. 43, no. 2, pp. 273-290, 2015.

[34] M. E. Warner and G. Bel, "Competition or monopoly? Comparing privatization of local public services in the us and Spain," Public Administration, vol. 86, no. 3, pp. 723-735, 2008.

[35] I. Yitmen, I. Akiner, and I. Tekce, “Applicability of second generation public private partnership projects in turkey: a conceptual framework," in Proceedings of the International Conference on Innovation in Architecture, Engineering \& Construction, São Paulo, SP, Brazil, August 2012. 
[36] J. M. Alonso and R. Andrews, "How privatization affects public service quality: an empirical analysis of prisons in england and wales, 1998-2012," International Public Management Journal, vol. 19, no. 2, pp. 235-263, 2015.

[37] S. Lenferink, T. Tillema, and J. Arts, "Towards sustainable infrastructure development through integrated contracts: Experiences with inclusiveness in Dutch infrastructure projects," International Journal of Project Management, vol. 31, no. 4, pp. 615-627, 2013.

[38] M. K. Lewis, Risk Management in Public Private Partnerships, 2001.

[39] O. Debande, "Private financing of transport infrastructure an assessment of the UK experience," Journal of Transport Economics \& Policy, vol. 36, no. 3, pp. 355-387, 2002.

[40] X. Zhao, B. G. Hwang, and W. Phng, "Construction project risk management in Singapore: resources, effectiveness, impact, and understanding," KSCE Journal of Civil Engineering, vol. 18, no. 1, pp. 27-36, 2014.

[41] G. Wu, J. Zuo, and X. Zhao, "Incentive model based on cooperative relationship in sustainable construction projects," Sustainability, vol. 9, no. 7, p. 1191, 2017.

[42] K. Muralidharan and M. Kremer, "Public and private schools in rural India," Electrochimica Acta, vol. 31, no. 2, pp. 273275, 2009.

[43] C. C. Ragin, Redesigning Social Inquiry: Fuzzy Sets and Beyond. Redesigning Social Inquiry: Fuzzy Sets and Beyond, University of Chicago Press, Chicago, IL, USA, 2010.

[44] S. Verweij and L. M. Gerrits, "How satisfaction is achieved in the implementation phase of large transportation infrastructure projects: a qualitative comparative analysis into the A2 tunnel project," Public Works Management \& Policy, vol. 20, no. 1, pp. 5-28, 2014.

[45] S. Verweij and L. Gerrits, "Understanding and researching complexity with qualitative comparative analysis: evaluating transportation infrastructure projects," Evaluation, vol. 19, no. 1, pp. 40-55, 2013.

[46] B. Rihoux and C. C. Ragin, Configurational Comparative Methods: Qualitative Comparative Analysis (QCA) and Related Techniques: Configurational Comparative Methods, Sage, Newcastle upon Tyne, UK, 2009.

[47] C. Q. Schneider and C. Wagemann, "Set-Theoretic methods for the social sciences: a guide to qualitative comparative analysis," International Journal of Social Research Methodology, vol. 16, no. 2, pp. 165-166, 2012.

[48] S. E. Skaaning, "Assessing the robustness of crisp-set and fuzzy-set QCA results," Sociological Methods \& Research, vol. 40, no. 2, pp. 391-408, 2011.

[49] R. M. Ryan and E. L. Deci, "Intrinsic and extrinsic motivations: classic definitions and new directions," Contemporary Educational Psychology, vol. 25, no. 1, pp. 54-67, 2000. 


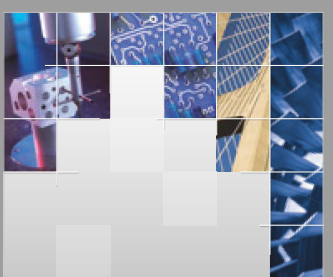

\section{Enfincering}
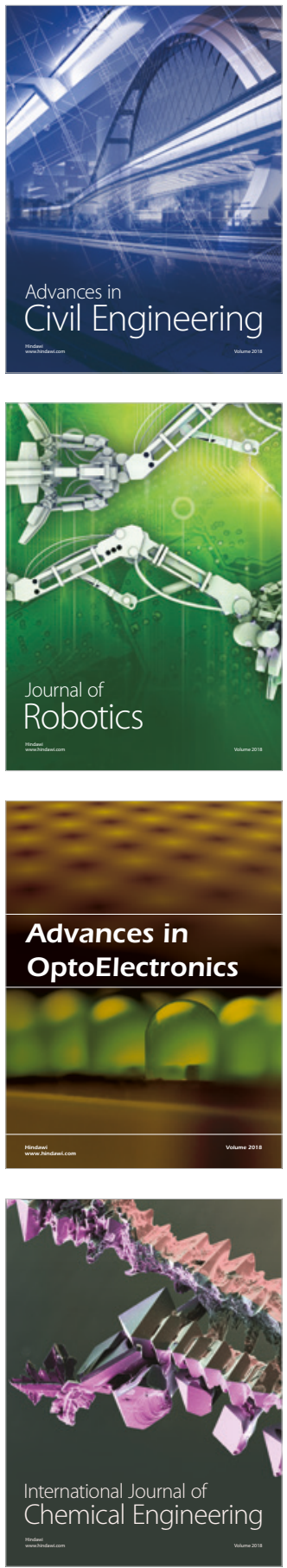

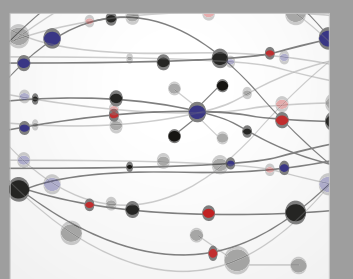

\section{Rotating \\ Machinery}

The Scientific World Journal

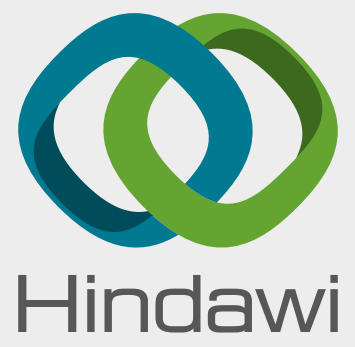

Submit your manuscripts at

www.hindawi.com
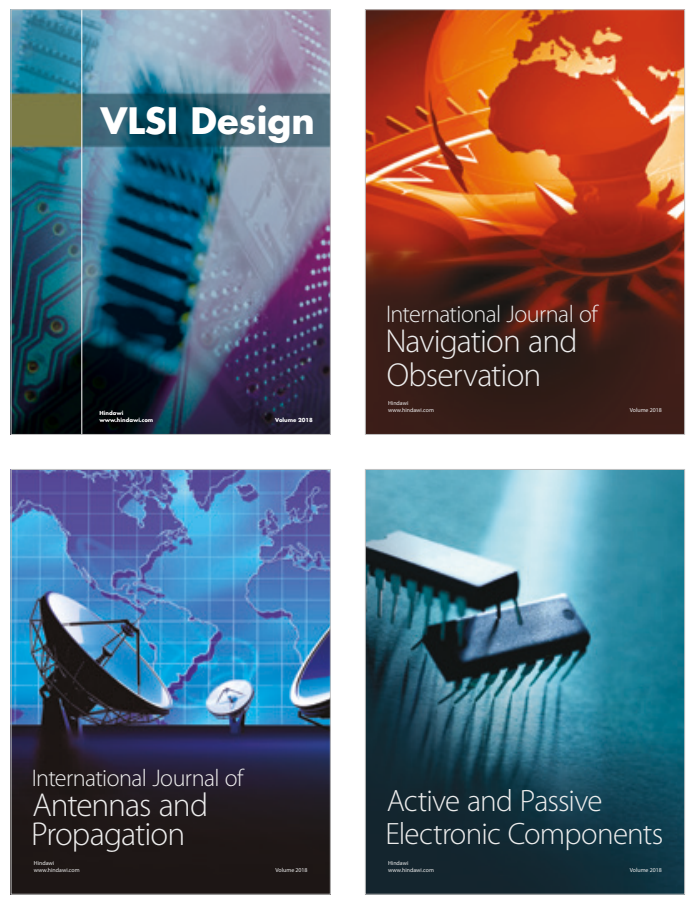
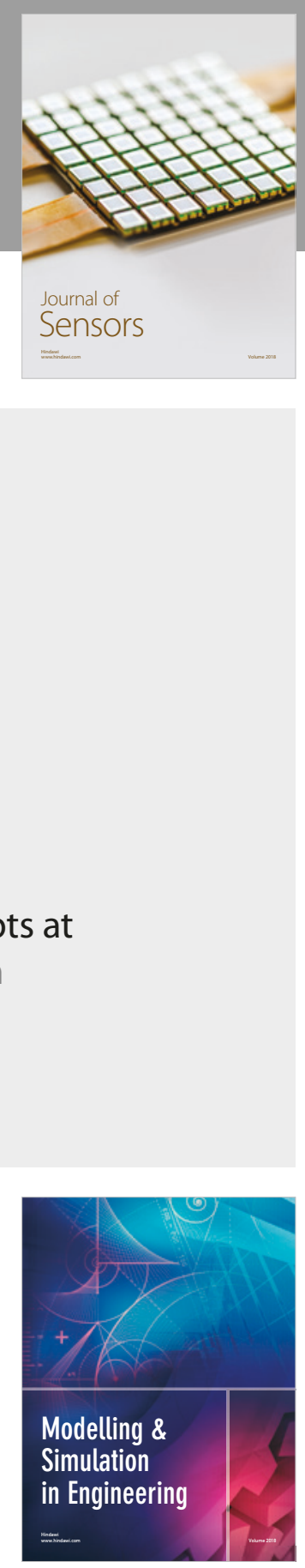

\section{Advances \\ Multimedia}
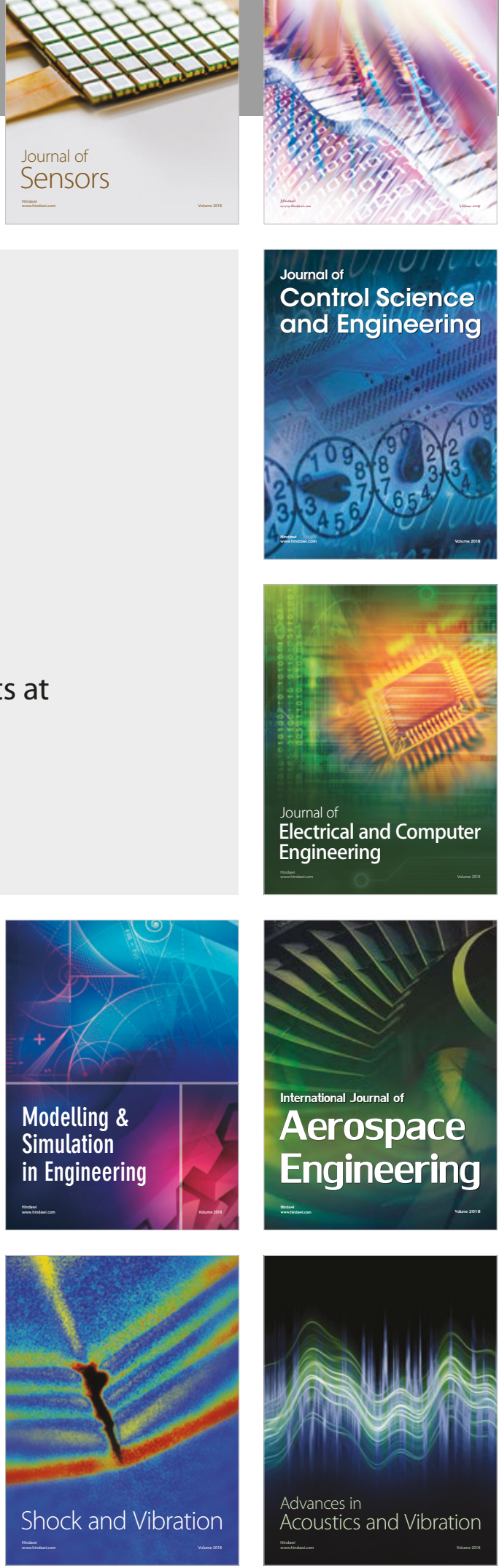